\title{
Heat Exchangers Networks Synthesis and Optimisation Performed by an Exergy-Based Expert Assistant
}

\author{
Massimo MAIORANO, Enrico SCIUBBA \\ Department of Mechanical and Aeronautical Engineering \\ University of Roma 1 - La Sapienza - Italy
}

\begin{abstract}
This paper presents a novel method for the design of "optimal" (or quasi-optimal) Heat Exchanger Network (HEN). The method consists of an Expert System (ES) based on a small number of powerful and strongly selective heuristic rules. The important contribution of this study lies in the formulation of the rules (that have been adapted from the existing literature) as logical propositions, and in their subsequent implementation in a prototype ES that performs interactively with the user. There is a high demand for an "automatic" (in some sense) methodology that may conveniently be adapted to designand-optimisation problems. Pinch Technology (PT), at present the most widely adopted design procedure, is very successful in most types of applications (except in cases where mechanical and thermal power must be optimised concurrently), but it constitutes an operative tool, and assumes that the user is already familiar with the design of HEN. The approach presented in this paper is entirely different: we do not "mask" the thermodynamic and thermo-economic principles that guide the engineer in the path towards the "optimal" HEN configuration, and do not allow concerns about "user friendliness" to impair the necessary participation of the user to the HEN synthesis procedure. In fact, though ES of this work (which we prefer to call "Expert Assistant", to underline its peculiarity of constantly interacting with the user) is still lacking many of the capabilities that a good designer possesses, the underlying procedure is, unlike any of the other existing Design-and-Optimisation Procedures, entirely inspectable by the user about its decision-making rules. It can be interrogated about its decision making, so that the logical path followed from the design data to the final solution can be inspected at will, and it can be used to directly compare different alternatives in a logically systematic fashion. The paper begins with a brief review of the HEN design problem, followed by a critical discussion of the heuristic rules that form the basis for the Inference Engine of the Expert System. The formalisation of these rules into logical propositions suitable for Knowledge Based Methods is then presented, and the resulting macrocode developed. As a preliminary validation, two examples of application of the code (named Heat Exchanger Network Expert Assistant, HENEA for short) are presented and discussed: since both cases are published, and their "optimal" solutions are known, the performance of HENEA can be assessed by comparison.
\end{abstract}

Key words: heat exchanger networks, process synthesis, expert systems for thermal design

\section{Introduction}

A Heat Exchanger Network (HEN) is a system that enables several streams to exchange sufficient amounts of thermal energy so that they can attain the respective temperature values ("targets") specified by process requirements. A HEN is therefore structurally implemented as an interconnected set of liquid or gaseous streams interacting in such a way that some of them (the acceptors) gain a certain amount of energy in the form of sensible or latent heat at the expenses of the others (the donors). This thermal exchange obviously takes place in heat exchangers, and therefore it is more convenient to regard a HEN as a system of heat exchangers connected through their inputs and outputs. The two descriptions are of course functionally equivalent: but the second one is more suitable for developing an Artificial Intelligence (AI) application to the design (synthesis) of a HEN. 
A typical HEN design problem is formulated as follows: given a process that contains $\mathrm{S}$ streams that need heating or cooling, and a set of targets, i.e. of specifications of the physical and thermodynamic conditions of each stream in each representative section of the process, devise a system of interconnected heat exchangers (HEN) such that:

a) all specifications are met

b) the HEN is "optimal" with respect to a welldefined objective function;

c) the direct and indirect constraints dictated by any larger industrial process the HEN may be inserted in are abided by.

The $\mathrm{N}_{\mathrm{u}}$ heat donors and the $\mathrm{N}_{\mathrm{c}}$ heat acceptors are called "hot-" and "cold streams" respectively; in addition, there are in general "hot" and "cold" utilities, i.e., $\mathrm{N}_{\text {hu }}$ high temperature sources that may be used for heating (some of) the cold streams, and $\mathrm{N}_{\mathrm{cu}}$ heat sinks (usually, cooling water or air at ambient temperature) that may be used for cooling (some of) the hot streams. The problem is invariably burdened by casedependent complications that are not apparent in the elementary formulation presented here: some of the fluids may experience phase changes; most fluids have temperature-dependent physical properties; under certain circumstances heat exchangers of the "mixing" type may be considered; the heat exchange coefficients vary with the type of flow; there are certain restrictions on the actual configuration of a heat exchanger, etc. HEN design is therefore a very complex problem, and we have decided to drastically simplify its formulation, in an effort to reduce the extent of the solution space. Accordingly, the following assumptions have been made:

1. there is no phase change in any of the heat exchanging processes;

2. the temperature dependency of the physical properties of all fluids may be neglected;

3 . only surface, counterflow heat exchangers constitute the HEN;

4. both external losses (conduction/convection to the immediate surroundings) and changes in the kinetic or potential energy of the fluids may be neglected;

5. Non-thermodynamic constraints (stability, flexibility, safety, and maintainability) have been ignored.

These assumptions are quite severe, in that they impose strong restrictions on the type and number of feasible configurations: but this is exactly our goal in this preliminary application. This is a validation study: if we want to treat problems with a significant number of streams (say, up to 10 donors and 10 acceptors), a mathematically complete analysis of the problem (necessary to check upon the correctness of the solution generated by HENEA) becomes intractable in practice, and the simplifying assumptions of the above list are necessary if we want to maintain full control on the inspectability of a prototype Expert System.

The literature on HEN design procedures is very extensive, and reviewing it is a difficult task: probably the most useful classification is one made on the distinction between mathematical (combinatorial) and physical (energy and/or costing) approaches, and this is the one which will be followed here.

\subsection{The combinatorial approach}

Consider the problem of choosing the "optimal" $\mathrm{HEN}$ as formulated in the previous Section. Each feasible configuration must be considered as a separate "system", and the problem can thus be restated as one of finding the proper connectivity of such a system. This amounts to devising all possible layouts (pairings between different streams), and then selecting the one that extremises the given objective function. Once the problem is posed this way, the first approach which comes to mind is of course a "brute force" combinatorial method: the idea being that of constructing all of the possible combinations of heat exchangers that meet the mass- and energy specifications, computing the objective function for each one of them, and selecting the "optimal" one. This corresponds in practice to an exhaustive scanning of the solution tree: in the first two decades of research in this field, there was a strong confidence that this was indeed the only possible line of action, and that the solution could be obtained by "complete", automated mathematical methods. Consequently, many of the early methods proposed for the HEN design selection were based on a combinatorial approach, tempered by some appropriate heuristics aimed at the reduction of the size of the solution space. Dynamic programming, several types of "pruned combinatorics" (that attempted to reduce the number of "feasible" configurations by discarding a priori the highest possible number of combinatorially acceptable solutions), "superstructure" analysis (that considered an initial configuration composed of a large number of Heat Exchangers and then used a technique similar to the so-called "simulated annealing" to reduce its complexity), branch-and-bound and Linear Programming methods have all been applied, with a varying and not always satisfactory degree of success, to the HEN Design problem. A critical review of these attempts is presented in (Gundersen and Näss 1988, Hohmann 1971). For the pur- 
purpose of the present study, the Pho and Lapidus (1973) and the Ponton and Donaldson (1974) methods must be mentioned here. The first one consists of a systematic tree-scanning technique in which a "configuration matrix" is constructed at each step for each (temporary) solution, and a series of heuristic rules, based in part on physical considerations, is used to discard single nodes or entire branches of the solution tree. The second one introduces some "engineering heuristics" which resemble some of the "Second Law reasoning" which is advocated in this paper. The general attitude of the supporters of combinatorial approaches was that, with increasing computer resources, it would be possible to overcome the difficulties generated by the numerical extension of the solution space (i.e., by the very large number of possible solutions). It is known now that the size of the vast majority of practical problems makes a purely combinatorial approach, unless very strongly pruned, unfeasible: all combinatorial procedures would inevitably lead to an extraordinary consumption of computer resources even if applied to problems with a relatively small number of Heat Exchangers, and would therefore be very expensive. Actually, it can be shown that any method based on a combinatorial technique is mathematically intractable, because the computational resources required by its solution grow with the factorial of the number of streams: therefore, the solution tree becomes so complex that it prohibits at all any kind of combinatorial approach to the HEN Design problem. In practice though, human designers do not rely on pure combinatorics, and try to introduce some heuristics in the search: the design rules they make use of are often vague, always qualitative, and reflect their own experience with "similar" problems. It is well known that the difference between an "expert" and a "novice" HEN designer is indeed detectable by examining the type and complexity of the applied heuristics. It took some time to actually understand that the most convenient design guidelines would be those based on thermodynamic considerations: as a matter of fact, the first work that tackled the problem from this point of view was that of Hohmann (Hohmann and Lockhart 1976), which was given very little attention at the time of its first publication, and for many years after that. Today, mathematical methods alone are no longer proposed: they are invariably coupled with some form of very strong heuristics, mostly based either on First Law considerations (Pinch methods (Linnhoff and Alanis 1991)), or on economic targeting (Mikkelsen and Quale 1997), on "evolutionary genetic operators" (a clever pseudo-annealing technique) (Wang et. al. 1995), or, in a thermodynamically more correct fashion, on the so-called Second Law techniques (Szargut and Sama 1995).

\subsection{Approaches based on physical reasoning}

An impressive systematic approach to the HEN design problem from a physical point of view was that proposed by Hohmann and Lockhart (1976). There were many remarkable novel features in Hohmann's work, and this makes it even more difficult to understand why it could be neglected for so many years: he was the first to introduce a feasibility table that allowed for the calculation of the so-called Minimum Energy Requirement ("MER") network, defined as the network in which the maximum amount of heat is exchanged within the HEN between the hot and cold streams, and consequently the required heating and cooling loads from external utilities are minimised. He also showed that for this particular MER network it was possible to calculate the utility requirement (external load) a priori, independently of the actual network connectivity: this could be done with the help of a $\mathrm{Q} / \mathrm{T}$ diagram (where $\mathrm{Q}$ is the exchanged heat and $\mathrm{T}$ the temperature at which the exchange takes place), by which one could correctly pair hot and cold streams according to their initial and target temperatures, to minimise the utility load. If the total amount of heat exchanged among streams is known, then the total heat exchanger area can be calculated once the overall heat exchange coefficient $\mathrm{U}$ and the minimum $\Delta \mathrm{T}$ are given. Hohmann also showed, by a simple energy balance, that in the energy/area plane (Figure 1) there is an entire region of "unfeasible" configurations: in this region the required amount of heat cannot be exchanged, regardless of the chosen layout. The remaining portion of the plane is spanned by lines of constant overall heat transfer coefficient, and the total area A (the sum of the active area of all heat exchangers) is -for each value of Q- inversely proportional to the product $\mathrm{U} \Delta \mathrm{T}$. Hohmann's most popular contribution, the so-called "minimum number rule", was originally derived as the number necessary in the case in which each stream reached its target temperature after one pass ${ }^{1}$.

\footnotetext{
${ }^{1}$ Actually, it was known to Hohmann, and was later shown rigorously by Linnhoff ((Linnhoff and Alanis 1991, Mikkelsen and Quale 1997): the " $N-1$ " rule of Pinch Technology is the direct translation of Hohmann's rule), that this minimum number is only indicative. There are in fact cases (presence of subsets (Sama 1995b)), in which it is possible to construct HENs having less Heat Exchangers than the "minimum" number. There are other cases, however (presence of loops (Linnhoff 1986,Szargut and Sama 1995)), in which the Hohmann number cannot be attained at all. It is important that a note will be made here of such limitations, to which authors will return in Sections 2.1 and 3.2.
}

Int.J. Applied Thermodynamics, Vol.3 (No.1) 


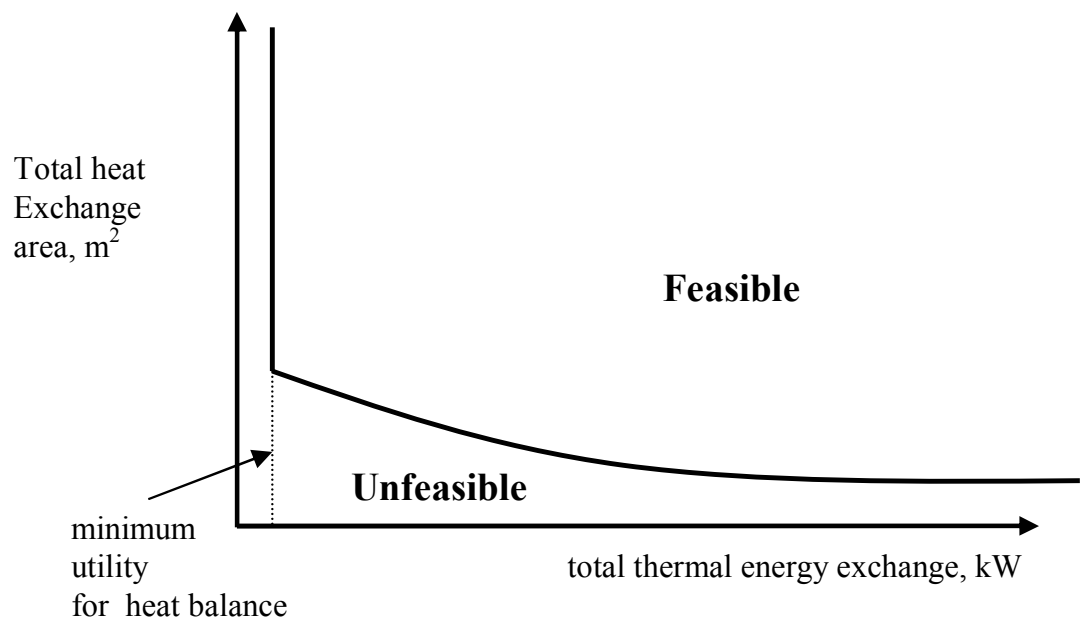

Figure 1. Hohmann's "feasible region" map.

Hohmann did not make explicit reference to Second Law principles, but some of his "design suggestions" can be directly related to the principle of minimising the entropy dissipation rate. During the rest of the ' $70 \mathrm{~s}$, no particular attention was paid to Second Law considerations, because other powerful concepts were being applied to design procedures, and all of these concepts were basically expressions of the First Law alone. The composite curve in the T/Q plane, in which all hot streams are represented by a single heatdonor line, and similarly the cold streams by a heat-acceptor line, was first introduced by Huang and Elshow (Huang and Elshout 1976), but it was undoubtedly perfected and rationally applied in a systematic fashion by Linnhoff in an long series of papers on this topic (of which (Ahmad and Linnhoff 1984, 1986, Linnhoff 1986, Linnhoff and Alanis 1991) are only a few). Linnhoff's work was later developed into a commercially available numerical package, and constitutes a very efficient, precise, robust and flexible HENdesign method which, in spite of the claims of its supporters, is not a Second Law based method. In effect, it fully exploits and rationalises the concept of the composite curve, and splits the T/Q plane into two regions (Figure 2) separated by the so-called Pinch Temperature (which gave the name to the method); then, essentially massand energy balances are used to construct the HEN, together with some costing rules which express the contrasting trends of the capital (total heat exchanger area) and operating (utilities) costs. Therefore, it is important to remark that no Second Law insight is needed, nor embedded in the method (see Sama (1995b) for a comprehensive critique). The remarkable practical and commercial success of Pinch Methods set back for a while every other HEN design procedure: only "corrected" Linear Programming proce- dures, in which some of the constraints were expressions of energy balances or of cost-related considerations, were proposed with varying degree of success (Mikkelsen and Quale 1997, Pho and Lapidus 1973, Ponton and Donaldson 1974). In more recent years, cost-related considerations were introduced into Pinch Analysis as well, following a method previously formulated by Gundersen and Näss (1988). This enabled the designer to establish an "optimal $\Delta \mathrm{T}$ " prior to actually choosing and sizing the HEN: this has been renamed Supertargeting (Ahmad and Linnhoff 1986). In these very same years, though, cost optimisation was being rigorously combined with First- and Second Law analyses by the so-called Thermoeconomic Optimisation procedures (Bejan et.al. 1996), a modern development of a concept first proposed by Tribus in the '60s but which took over twenty years to obtain the recognition it deserves. Unfortunately, there is no general standard numerical procedure based on Thermoeconomics capable of performing well in HEN applications, and therefore most of the socalled "Second Law Methods" are ad-hoc procedures, that need to be applied by -or under the guidance of- a very knowledgeable Applied Thermodynamicist. Not surprisingly therefore, Thermoeconomic methods, in spite of their obvious and well-proven (Gaggioli et. al. 1991, Sama 1995b) superiority, are not as widespread as Pinch Analysis.

\subsection{Artificial Intelligence approaches}

The "Artificial Intelligence" approach taken here can be at best described as a low-level one: In this case the goal has been that of reproducing the logical blocks of the design procedure a human "expert Process Designer" would follow when tackling a HEN design problem. Right 
from the onset, it has been noticed that, oddly enough, AI methods have already been employed for years in the design of HEN: only, those who did so were not aware of it! For instance, the socalled Ponton and Donaldson method (Ponton and Donaldson 1974) consists of a certain number of "design rules" that aim at the minimisation of the heat exchange area and of the utility load at the same time: this apparently contradictory task can be carried out by making use of a set of design guidelines that are a clear expression of their Authors' expert judgement gained by careful study of the problem. Similarly, while apparently unaware of the striking similarity of their reasoning patterns with the principles of AI, all Authors of heuristics-based methods struggle to distil from their own experience a limited number of "absolute rules" which could be assembled into a sequence of alternative guidelines to a "general HEN design procedure". Even Pinch Technology, which can be properly taken as an example of a structured and codified procedure, was never regarded as the practical, though certainly not systematic, example of application of AI procedures, which it really is! Finally, all the so-called Second Law techniques (Gaggioli et. al. 1991, Garland 1996, Ngaw 1998, Sama 1995a, 1995b) are in essence unstructured applications of the thermodynamic insight of their authors. It is the desire of the authors to stress this remarkable fact, because they will capitalise on it in the next Sections. Formal AI applications were proposed only very recently, by Chen and Shen (1989), Bi and Ma (1997), Wang et al. (1995), and Sciubba and Melli (1998); the last two references also present two different examples of a design application environment.

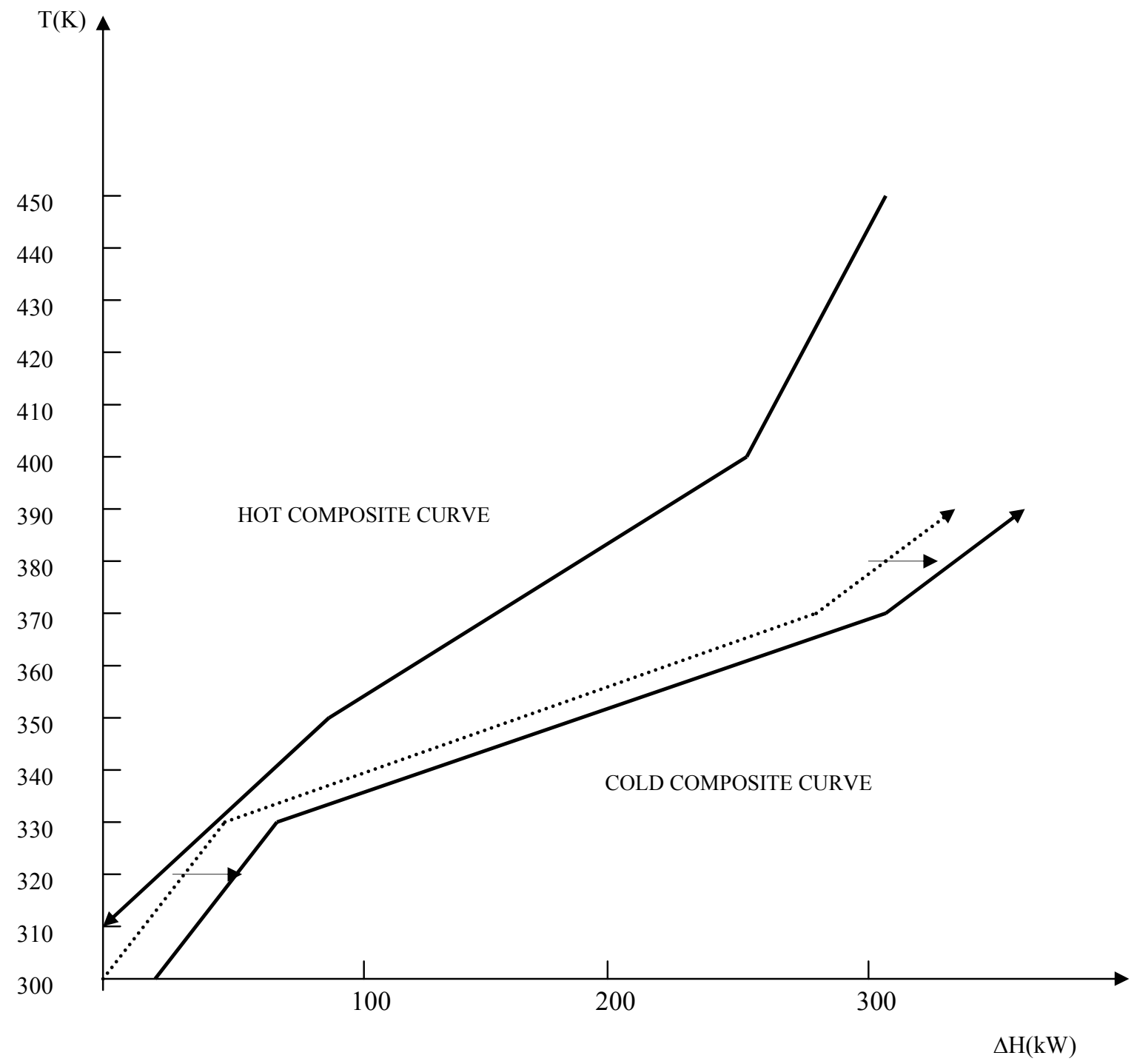

Figure 2. Hot and cold composite curves 


\section{The Development of a HEN-Expert As- sistant}

The process of constructing an Expert System is a complex and multi-faceted one: for a description geared towards Thermal Systems Designers, the reader is referred to (Sciubba and Melli 1998). Here, we shall attempt to simplify the treatment by dividing it into its three main logical steps: the compilation of a list of the "Design Criteria" we want the code to enforce; their formal implementation into a set of "rules" that constitute a logical macro-code and the practical linking of these rules within a coding frame that constitutes the resulting Expert System.

\subsection{The general design criteria}

To gather enough theoretical and practical information about design guidelines is a difficult and cumbersome task: difficult, because it subsumes direct and unrestricted access to "expert knowledge", and cumbersome, because most of this knowledge does not exist in Design Books, but must be obtained by a systematic review of the pertinent technical literature and a critical recourse to direct interviews with Domain Experts (designers with a documented and extensive experience in the specific field). Knowledge Acquisition per se is a broad topic, and it is not within the purposes of this paper to describe our knowledge-gathering process: what one can say here is that, after a comprehensive analysis of a sufficient number of pertinent sources, the following general criteria were established as necessary to the proper functioning of an Expert System:

1. The best known limitation, and the first that ought to be considered, is that expressed by the so-called "Hohmann rule" (Hohmann 1971), which is founded on some energy-based arguments and prescribes a minimum number of Heat Exchangers in the HEN. This "minimum number rule" also limits indirectly the total number of systems to include in the calculations, because it is reasonable to explore in detail only those configurations having a total number of heat exchangers in the immediate vicinity of the minimum. It must be noticed that, as it was clearly shown by Linnhoff (Linnhoff 1986), a desirable configuration of a HEN is the one without heat transfer across the pinch: such a structure is called the maximum energy recovery configuration ("MER" for short), and may include some loops, i.e., multiple links intentionally established between two or more streams to prevent heat flow across the pinch. Any HEN structure that includes loops has by force a higher number of heat exchangers than this "minimum" (see footnote 1). For practical purposes, this rule ought therefore to be imposed as a weak approximate constraint, and the formulation we propose here is:

I Design Criterion: The number of heat exchangers in a HEN must be in the immediate vicinity of $N_{\text {min }}$ given by Hohmann's rule

How "immediate" this vicinity must be is left for the time being to the designer's experience: we shall try to rationally quantify the interval later in this paper.

2. One can make use of additional basic thermodynamic considerations, the first one being:

II Design Criterion: The transfer of heat from a cold stream to a hot one is prohibited

Though seemingly obvious, this rule is in no way enforced by a combinatorial approach.

3. Another undesirable feature to avoid is the reheating of a stream that has been previously cooled, because this practice would clearly add to the global irreversibility losses of the system (Sama et.al. 1989). This can be expressed by

III Design Criterion: Re-heating of previously cooled streams is prohibited

And by its symmetrical rule for cold streams:

IV Design Criterion: Re-cooling of previously heated streams is prohibited

4. The use of cold utilities to cool hot streams above the pinch ought to be avoided, because this is equivalent to exchanging heat across the pinch. This result is shown clearly by Pinch Technology considerations, but it was well known before, being in fact a violation of an optimal application of the Second Law (which dictates that the $\Delta \mathrm{T}$ between streams be minimised). The resulting rule is:

$V$ Design Criterion: Cooling of hot streams above the pinch by means of cold utilities is prohibited

Again, there is a symmetric expression for the cold streams:

\section{Design Criterion: Heating of cold streams below the pinch by means of hot utilities is prohibited}

5. When coupling two streams, the irreversible losses are reduced if the Approach Temperature Difference ("ATD") is relatively small (this is also a direct application of Second Law considerations). This condition can be enforced as a weak constraint:

VII Design Criterion: Configurations that include heat exchangers with an ATD larger than a pre-set maximum are prohibited 
6. On the other hand, if after having been coupled, two streams exit the heat exchanger with a very small temperature gap, it is likely that valuable heat exchanger area is being inefficiently used. This can be avoided by limiting the Terminal Temperature Difference (TTD):

VIII Design Criterion: Configurations that include heat exchangers with a TTD smaller than a pre-set minimum are prohibited

7. Finally, it would be good engineering and thermodynamic practice to assign a priority to the coupling of streams, trying to match first those with not-so-distant temperature levels:

IX Design Criterion: If a stream is an acceptor, the first donor to be tried for the pairing ought to be the hot stream with the exit target temperature closest to the inlet temperature of the acceptor

This rule, too, has a counterpart for hot streams:

$X$ Design Criterion: If a stream is a donor, the first acceptor to be tried for the pairing ought to be the cold stream with the exit target temperature closest to the inlet temperature of the donor

Additional, in a sense more general rules are clearly required, and their choice is a matter of "taste": These authors' own experience in Thermal Systems Synthesis lead them to apply the so-called "common sense Second Law rules" suggested in (Sama et.al. 1989), and later augmented in (Bejan et.al. 1996,Szargut and Sama 1995). It is important to remark that pragmatism ought to guide the decision here, and that a different set of rules should be adopted if it can be demonstrated that it can lead to an equivalent solution with a smaller computational effort, or to a better result with the same computational effort. This said, the proposed set of rules that is chosen to complement the ten Design Criteria is the following (list adapted from (Szargut and Sama 1995)):

$X I$ avoid whenever possible the mixing of streams; if mixing is unavoidable, avoid bringing in contact streams with substantial differences in temperature, pressure or chemical composition;

XII do not discard, directly or indirectly, heat at high temperature into the environment;

XIII avoid whenever possible the exchange of heat between streams with large difference in flow heat capacity (product of the mass flow rate with the heat capacity);

$X I V$ when exchanging heat between two streams, minimise the use of intermediate heat transfer fluids;
$X V$ the economic optimum $\Delta T$ of a heat exchanger is directly proportional to the average temperature of the exchange (measured for example by the LMTD);

XVI avoid whenever possible the throttling of steam and gases;

XVII rank the irreversibility potential of the streams: the higher the mass flow rate, the larger the possibility for losses (and for improvement!);

XVIII use simplified exergy consumption calculations as a guide to process modifications;

XIX some Second Law irreversibilities can be avoided, others cannot: concentrate on those that can.

These quite simple and qualitative criteria are likely to produce a very strong pruning of the configuration tree, at the cost of some additional computational effort (both the ATD and the TTD must be calculated by preliminary energy balances). Nevertheless, the number of alternative configurations to examine would still be prohibitively high: for a $(10+10)$-stream case, approximately 250000 different configurations must be designed and compared ${ }^{2}$. Several methods have been proposed in the last three decades to solve the "Optimal HEN Problem" (for a comprehensive, though not very recent, review, see (Gundersen and Näss 1988)), and one of the most important outcomes of the ensuing rich and lively debate is that the very same definition of an "Optimal HEN" should be subject to scrutiny in the course of the problem formulation, because different choices (Minimal Area, Maximum Energy Recovery, Minimal Initial Cost) can lead to the exploration of entirely different branches of the (a priori unknown) configuration tree. We shall not try to generate an Expert HEN Designer (i.e., an ES that solves automatically the synthesis-and-optimisation problem), and take a pragmatic approach instead: our aim here is to build an Expert Assistant to the HEN designer (Sciubba and Melli 1998,Stephanopoulos 1986), that can guide the engineer in the search process through the configuration tree, and guarantee the attainment of at least a quasi-optimal configuration under the specified objective function. It can be anticipated that this Expert Assistant can be constructed by using a rather limited number of very powerful rules, instead of a large number of

\footnotetext{
${ }^{2}$ This figure has been obtained assuming that the minimum number of HE as given by Hohmann's rule is equal to 21, that all unphysical pairings (those for which both streams are donors or both are acceptors and those for which there exists a thermal incompatibility) are preliminarily discarded, and that each single stream may cross more than one heat exchanger.
} 
specific rules of limited range: this is due to the fact that the particular set of rules adopted here has been "distilled" from the aggregate knowledge of generations of HEN Designers and Thermodynamicists, and therefore represents deep rather than superficial Procedural Knowledge (Sciubba and Melli 1998).

\subsection{Formulation of the physical problem}

Consider $S$ fluid streams: $N_{h}$ heat donors that must be cooled and $N_{c}$ heat acceptors that must be heated, each one to a specified temperature. The following knowledge is also available:

1. Mass flow rates, initial temperatures, heat capacities and physical properties of each stream are known;

2. The final temperature of each stream ("target temperature") is specified by process requirements. If these targets are weak (i.e., they are expressed by inequalities, like " $\mathrm{T}_{\mathrm{j}} \leq \mathrm{T}_{\max }$ "), or if they are process-dependent, a base configuration will be chosen for which the targets represent strong constraints;

3. Both the availability and the cost of the utilities, i.e., the process streams that may be used as heat sources and sinks for the HEN are known. Furthermore, their cost structure is also known, so that variations in utility requirements may be correctly priced;

4. Capital and operating costs of all equipment directly used in the HEN (pumps, valves, pipes, structures and heat exchangers), as well as marginal capital- and operating costs of all equipment that can be indirectly affected by the HEN performance are known;

5. Heat exchange coefficients are assigned. Since they depend on the individual Heat Exchanger configuration, only approximate averaged values are available at the time of problem formulation: in the course of the design, these initial values may be recalculated with closer approximation.

The solution is achieved by choosing the optimal HEN configuration, according to the specified objective function. Consider the process described in TABLE II (this example has been adapted from (Bejan et.al. 1996)): there are 2 cold- and 2 hot streams, and therefore the extension of the purely combinatorial problem would be $\mathrm{N}_{\mathrm{HEN}}=24$. The minimum number of Heat Exchangers that will constitute the HEN is given by the Hohmann formula:

$$
\mathrm{N}_{\min }=\mathrm{N}_{\mathrm{h}}+\mathrm{N}_{\mathrm{c}}+\mathrm{N}_{\mathrm{hu}}+\mathrm{N}_{\mathrm{cu}}-1=2+2+1+1-1=5
$$

in which $\mathrm{N}_{\text {hu }}$ and $\mathrm{N}_{\mathrm{cu}}$ represent the number of hot and cold utilities respectively, for each one of

\section{Int.J. Applied Thermodynamics, Vol.3 (No.1)}

which a separate heat exchanger must be inserted $^{3}$. A first rule in our Knowledge Base (KB) is therefore:

Rule 1): IF $\left(\mathrm{N}_{\text {he }}>\mathrm{N}_{\text {min }}\right)$

THEN (discard present configuration)

It will be noticed that there is a logical gap here: to apply Rule\#1, it is necessary that a "present configuration" already exists, i.e., that there is some "configuration generating" procedure. For the moment, it can be stipulated that any of the existing combinatorial methods may be used to generate, one by one, all possible initial configurations: it is guaranteed, by a correct application of the above rule, that only a small fraction of the "mathematically possible" configurations will be actually considered feasible by this Expert Assistant.

To proceed effectively in this path towards an optimal design, one can make use of other rules that express a different kind of knowledge about the problem. One needs rules that express the "deep knowledge" that an expert human designer makes use of when attempting to solve the problem: several sets of guidelines have been compiled, and some have been actually implemented in (deterministic) numerical codes that apply them in a pre-defined order to attain a solution. These codes are Problem Solvers, in that their path towards a solution is not influenced at all, or only in minimal part, by a direct involvement on the part of their users ${ }^{4}$. However, the approach which is taken here is somewhat different: it is, as stated above, trying to implement an Expert Assistant, whose task is not that of finding the solution in an autonomous way, but rather that of providing "suggestions" or "guidelines" to the user, who can accept the ES advice or make decisions on its own. The "translation" of these rules into propositional calculus cannot be directly implemented on a one-to-one basis: therefore, we shall first try to formulate a macro-code for the Expert Assistant, and then will show how the proposed rules relate to the 19 "thermodynamic" Design Criteria reported in Section 2.1. A brief explanation is added to each one of the rules presented here.

Rule 2): IF (ATD $>\Delta \mathrm{T}_{\text {max,spec }}$ )
THEN (discard present configuration)

\footnotetext{
${ }^{3}$ As it will be clear in the following discussion, this Expert Assistant ignores the exceptions to Hohmann's rule (see note 1 above).

${ }^{4} \mathrm{We}$ are referring specifically to codes developed along the lines of the so-called Pinch Technology $(2,3)$, which is by far the most successful (deterministic) tool available today to solve HEN Design problems: there are though a number of equally successful solvers based on different approaches, which are somewhat more difficult to use and therefore not so popular among engineers. For a review, see (9).
} 
This rule avoids wasting a thermodynamically valuable driving force, by introducing a coupling between streams at excessively different temperature levels. $\Delta \mathrm{T}_{\text {max,spec }}$ must be specified by the user, and is application-dependent.

Rule 3): IF (TTD $<\Delta \mathrm{T}_{\text {min,spec }}$ )

THEN (discard present configuration)

This rule avoids wasting heat exchange surface, by forcing two streams to exchange more heat than technically convenient. $\Delta \mathrm{T}_{\text {min,spec }}$ must be specified by the user, and depends on the type of heat exchanger employed.

Notice that both rule\#2 and rule\#3 require additional calculations, because to compute the ATD or the TTD for a specific coupling of streams it is necessary to solve the energy balance of the heat exchanger. Since, at least for a first run, it is possible to use average fluid properties and an average heat transfer coefficient, the computational economy resulting in the pruning of the configuration tree caused by the application of these rules is almost certainly higher than the additional computational expense, and justifies this portion of our paradigm.

Rule 4): $\boldsymbol{F O R}\left(\mathrm{j}=1, \mathrm{~N}_{\mathrm{cu}}\right)$ DO:

FOR $\left(\mathrm{i}=1, \mathrm{~N}_{\mathrm{h}}\right)$ DO:

IF $\left(\mathrm{T}_{\text {hot, in }}>\mathrm{T}_{\text {pinch }}\right)$

AND $\left(T_{\text {cold, in }}=T_{\text {cu, }, j}\right)$

THEN (discard present configuration)

This rule prohibits the exchange of heat between any hot stream above the pinch and a cold utility (the $j$-th one) which is below the pinch. Therefore, application of the rule is tantamount to prohibiting heat exchanges across the pinch between heat donors and cold utilities.

Rule 5): FOR ( $\left.\mathrm{k}=1, \mathrm{~N}_{\mathrm{hu}}\right)$ DO:

FOR $\left(\mathrm{i}=1, \mathrm{~N}_{\mathrm{c}}\right)$ DO:

IF $\left(\mathrm{T}_{\text {cold, in }}<\mathrm{T}_{\text {pinch }}\right)$

AND $\left(T_{\text {hot, in }}=T_{\text {hu,k }}\right)$

THEN (discard present configuration)

This rule is logically symmetric to the previous one and prohibits the exchange of heat between any cold stream below the pinch and a hot utility (the $k$-th one) which is above the pinch. Therefore, application of the rule is tantamount to prohibiting heat exchanges across the pinch between heat acceptors and hot utilities.

Rule 6): IF $\left\{\left(\mathrm{c}_{\mathrm{p}} * \mathrm{~m}\right)_{\text {hot }}>>\left(\mathrm{c}_{\mathrm{p}} * \mathrm{~m}\right)_{\text {cold }}\right\}$

THEN (split hot stream)

Rule 7): IF $\left\{\left(\mathrm{c}_{\mathrm{p}}^{*} \Delta \mathrm{T}^{*} \mathrm{~m}\right)_{\text {cold }}>>\left(\mathrm{c}_{\mathrm{p}} * \Delta \mathrm{T}^{*} \mathrm{~m}\right)_{\text {hot }}\right\}$ THEN (split cold stream)

These two rules can only be enforced after the energy balance of a heat exchanger has been calculated, and prohibit the coupling of two streams with very different heat capacities (which is thermodynamically not correct, because it leads to higher entropy generation). Notice that this is a decision taken in the realm of approximate knowledge: how much is the " $>>$ " worth must be decided case by case by the user. Also, notice that the actions "split hot stream" and "split cold stream" are complex actions, that need to be undertaken by an ad hoc subroutine: this independent sub-program must decide how to carry out the splitting, how to re-couple the streams, and so on. This is an action that goes against the goal of "minimising the number of configurations included in the search", because in reality rules 6 and 7 produce at least one more configuration each time they are enforced. Again, the reason for keeping these two rules in our KB is heuristic in nature: HEN design experience has shown that including stream-splitting in the procedure improves the efficiency of the HEN, by reducing overall irreversibility and producing a better (closer to "optimal") HEN configuration.

Rule 8): IF (stream is hot)

AND (it has been cooled in a previous step)

AND (it is being heated up in the present step)

THEN (discard present configuration)

Rule 9): IF (stream is cold)

AND (it has been heated up in a previous step)

AND (it is being cooled down in the present step)

THEN (discard present configuration)

These two rules improve the efficiency of the HEN in two ways: first, they implicitly exclude the possibility of heat transfer across the pinch; second, they avoid duplicating irreversibilities by re-heating a stream that had been cooled in a previous heat exchanger or re-cooling another that had been heated before. They also have an implicit effect of reducing the number of heat exchangers, by ensuring that a hot stream remains a heat donor and a cold stream a heat acceptor. Their enforcement though is quite resourceintensive from the computational point of view: it requires memory of past actions, which in computational terms means that all previous successful nodes of the configuration tree must be kept in the working memory.

Rule 10): IF (heat exchanger is of mixing type) AND $\left\{\left[\left(\mathrm{p}_{\text {hot }} » \mathrm{p}_{\text {cold }}\right) \mathbf{O R}\left(\mathrm{p}_{\text {hot }}\right.\right.\right.$ " $\left.\left.\mathrm{p}_{\text {cold }}\right)\right]$ OR $\left(\mathrm{T}_{\text {hot }} »\right.$ $\mathrm{T}_{\text {cold }}$ ) OR (chemical compositions are widely different) $\}$

THEN (discard present configuration)

This rule avoids the mixing of streams with wide differences in pressure, temperatures or chemical composition, thus avoiding the associated irreversible losses. Notice that, as in rules 6 and 7, quantitative handling of approximate knowledge is required here. 
Rule 11): IF (stream is cold)

AND IF (it must be heated)

THEN (choose as heat donor the stream nearest to the prescribed exit target temperature)

Rule 12): IF (stream is hot)

AND IF (it must be cooled)
THEN (choose as heat acceptor the stream nearest to the prescribed exit target temperature)

These two rules are symmetric, and force a "ranking" of heat donors and acceptors such that the driving forces are minimised.

TABLE I EQUIVALENCE BETWEEN THE THERMODYNAMICAL AND THE PROPOSITIONAL RULES

\begin{tabular}{|c|c|c|}
\hline propositional rule 2 & is embedded in $(\subset)$ & design criterion VII \\
\hline propositional rule 3 & is embedded in $(\subset)$ & design criterion VIII \\
\hline propositional rules 4,5 & are embedded in $(\subset)$ & design criteria V, VI \& XII \\
\hline propositional rules 6,7 & are equivalent to $(\equiv)$ & design criteria XIII \& XVII \\
\hline propositional rules 8,9 & contain $(\supset)$ & design criteria III \& IV \\
\hline propositional rule 10 & is equivalent to $(\equiv)$ & design criterion XI \\
\hline propositional rules 11,12 & are equivalent to $(\equiv)$ & design criteria IX \& X \\
\hline
\end{tabular}

To check how the 19 Design Criteria may be enforced at this level, an equivalence table can be useful:

From TABLE I, it is clear that Design Criteria $I I, \mathrm{XIV}, X V, X V I I I$ and $X I X$ have no counterpart in our macrocode. The reason is that they express rules that are at a different conceptual level with respect to rules 1-12. Design Criteria $I I$ and $X I V$ can be implicitly enforced by a proper choice of the "configuration generator" (the combinatorial tool); criterion $X V$ can be directly inserted in the Knowledge Base: the cost data on the Heat Exchangers could include a weighing function which relates their optimal $\Delta \mathrm{T}$ to the LMTD. Criterion XVIII can be enforced procedurally in the deterministic portion of the code, the one that actually performs the calculations. Finally, criterion $X I X$ has been omitted here because it requires so much "insight" that its implementation would require yet another Inferential Engine at a meta-meta-level: even if it is conceivable to build such an ES, it is considered as more advisable to let the Expert Assistant stimulate the user's knowledge and insight by some interactive prompting, than to embark in the difficult task of developing a "General Thermodynamic Advisor".

The remaining functions (calculation of fluid properties, calculation of the average heat exchange coefficients, heat and mass balances, cost assessment, etc.) are easily performed by properly linked property and balance functions.

\subsection{Brief description of the code}

HENEA is a $\mathrm{C}++$ code that performs the following operations:

- accepts the design data and specifications with the help of an interactive (albeit still prototypical) Graphic User Interface ("GUI");

- sequentially builds the unknown solution tree, by successive and systematic applica-

10 Int.J. Applied Thermodynamics, Vol.3 (No.1) tion of the Pho-Lapidus enumeration algorithm (Pho and Lapidus 1973). In particular, the "synthesis matrix" for each configuration is produced at each step; note that the tree is built with a "depth-first" method, for reasons that will be soon clear;

- performs the "Hohmann test" on each newly generated configuration, and discards it immediately if the total number of heat exchangers is higher than $\alpha \mathrm{N}_{\text {min }}$. Here, $\alpha$ is a factor larger than 1 chosen by the user (see Section 3.1). If the configuration fails the test, then the entire branch following from it is discarded, because further addition of heat exchangers would of course make matters worse (this can be easily implemented if the solution is built "depth-first");

- calls an "energy balance" function that computes the pinch point, the heat capacity ratios and the actual $\Delta \mathrm{T}$ (assuming a user-specified value for the overall heat exchange coefficient);

- applies Rules 2 and 3 to discard configurations which do not abide by the ATD or TTD user-specified constraints;

- applies Rules 4 and 5 to discard configurations that would imply heat transfer across the pinch;

- applies Rules 10 and 11 to ensure that the pairing of the streams is efficient from a Second Law standpoint;

- applies Rules 6 and 7 to enforce stream splitting if the ratio of the flow heat capacities is higher than a user-specified value;

- for the surviving configurations, computes a total investment and operating cost, using user-specified formulas;

- builds a file, which contains the ordered sequence of the surviving configurations and of their total cost.

Notice that the Pho-Lapidus algorithm automati- 
cally enforces Rules 8 and 9 of Section 2.2.

\section{Examples of Application}

\subsection{A 4-stream HEN (Example 9.1 in} (Bejan et.al. 1996))

As a first test case, HENEA has been applied to a $(2+2)$-streams situation for which the design data are given in TABLE II. The numerical values of the constraints appearing in Rules 1-12 are specified in TABLE III.

The possibility of adopting Heat Exchangers of the mixing type will be neglected, so that Rule 10 does not apply. Furthermore, since the flow heat capacities of the cold and hot streams are not too far apart from each other, stream splitting can be disregarded, and thus Rules 6 and 7 do not apply either. Notice that the Pinch Temperature must be computed in advance to enforce Rules 4 and 5: in this sense, HENEA "builds on" Pinch Technology. The procedure is straightfor- ward: It generates a configuration tree (shown in Figure 3) and applies each Rule in turn to each configuration. TABLE IV shows the step-by-step results of the application of HENEA. The symbol ":- " following the numerical value of a constrained parameter indicates that the pertinent Rule is not satisfied (the value exceeds the imposed constraint).

The following remarks apply:

1. The Rules are selective enough: actually, they are overselective, because no configuration passes HENEA's screening. It is clear that some of the constraints must be relaxed.

2. Rule \#1 appears to be too strict: it might well be that a configuration with $\left(N_{\min }+1\right)$ Heat Exchangers is more convenient than one with $N_{\text {min }}$. Accordingly, we have reformulated this rule allowing for a derangement:

TABLE II DESIGN VALUES FOR EXAMPLE 3.1

\begin{tabular}{|l|c|c|c|}
\hline \multicolumn{1}{|c|}{ Stream } & Heat capacitv, $\mathbf{k W} /{ }^{\circ} \mathbf{C}$ & $\mathbf{T}_{\mathbf{i n}}, \mathbf{K}$ & $\mathbf{T}_{\text {aut }}, \mathbf{K}$ \\
\hline $\mathrm{H} 1$ & 1 & 450 & 350 \\
\hline $\mathrm{H} 2$ & 2 & 400 & 310 \\
\hline $\mathrm{C} 1$ & 1.8 & 300 & 390 \\
\hline $\mathrm{C} 2$ & 4 & 330 & 370 \\
\hline Hot utility, HU & $\infty$ & 500 & 500 \\
\hline Cold Utility, CU & $\infty$ & 300 & 300 \\
\hline
\end{tabular}

TABLE III VALUES OF THE CONSTRAINTS FOR THE PROPOSITIONAL RULES APPLIED IN EXAMPLE 3.1

\begin{tabular}{|l|c|c|}
\hline \multicolumn{1}{|c|}{ Constraint } & Rule where the constraint applies & Numerical value \\
\hline Minimum number of Heat Exchangers, $\mathrm{N}_{\min }$ & 1 & 5 \\
\hline Approach Temperature Difference, ATD & 2 & $50 \mathrm{~K}$ \\
\hline Terminal Temperature Difference, TTD & 3 & $10 \mathrm{~K}$ \\
\hline Pinch Temperature & 4,5 & $335 \mathrm{~K}$ \\
\hline
\end{tabular}

TABLE IV RESULTS OF THE APPLICATION OF HENEA TO EXAMPLE 3.1

\begin{tabular}{|c|c|c|c|c|c|}
\hline $\begin{array}{l}\text { Configur } \\
\text { ation }\end{array}$ & $\begin{array}{l}\text { Rule \# } 1 \\
\left(\mathrm{~N}_{\min }=5\right)\end{array}$ & $\begin{array}{c}\text { Rule \# } 2 \\
\left(\mathrm{ATD}_{\max }=50 \mathrm{~K}\right)\end{array}$ & $\begin{array}{c}\text { Rule \# } 3 \\
\left(\mathrm{TTD}_{\min }=10 \mathrm{~K}\right)\end{array}$ & $\begin{array}{c}\text { Rule \# } 4 \\
\text { (no cold utility above 330K) }\end{array}$ & $\begin{array}{c}\text { Rule \# } 5 \\
\text { (no hot utility below 340K) }\end{array}$ \\
\hline A1 & & & & : : & \\
\hline $\mathrm{A} 2$ & & $94.5 \mathrm{~K}$ & & :) & \\
\hline $\mathrm{A} 3$ & & & & : & :) \\
\hline A4 & & $95 \mathrm{~K}$ & & : & :) \\
\hline B1 & & $95 \mathrm{~K}$ & & & \\
\hline $\mathrm{B} 2$ & & $94.5 \mathrm{~K}$ & & (:) & \\
\hline B3 & & $94.5 \mathrm{~K}$ & & & \\
\hline B4 & 6 & & & : & \\
\hline B5 & & $94.4 \mathrm{~K}$ & & & \\
\hline B6 & & & & $\because:$ & $:$ \\
\hline B7 & & $95 \mathrm{~K}$ & & & \\
\hline $\mathrm{B} 8$ & & $95 \mathrm{~K}$ & & 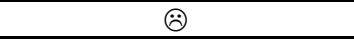 & $:$ \\
\hline $\mathrm{C} 1$ & & $94.5 \mathrm{~K}$ & & & \\
\hline $\mathrm{C} 2$ & 6 & $80 \mathrm{~K}$ & & : : & \\
\hline $\mathrm{C} 3$ & 6 & $64.4 \mathrm{~K}$ & & & \\
\hline $\mathrm{C} 4$ & & & & 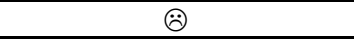 & \\
\hline $\mathrm{C} 5$ & 6 & & & :) & \\
\hline $\mathrm{D} 1=\mathrm{D} 2$ & 6 & $80 \mathrm{~K}$ & & & \\
\hline
\end{tabular}




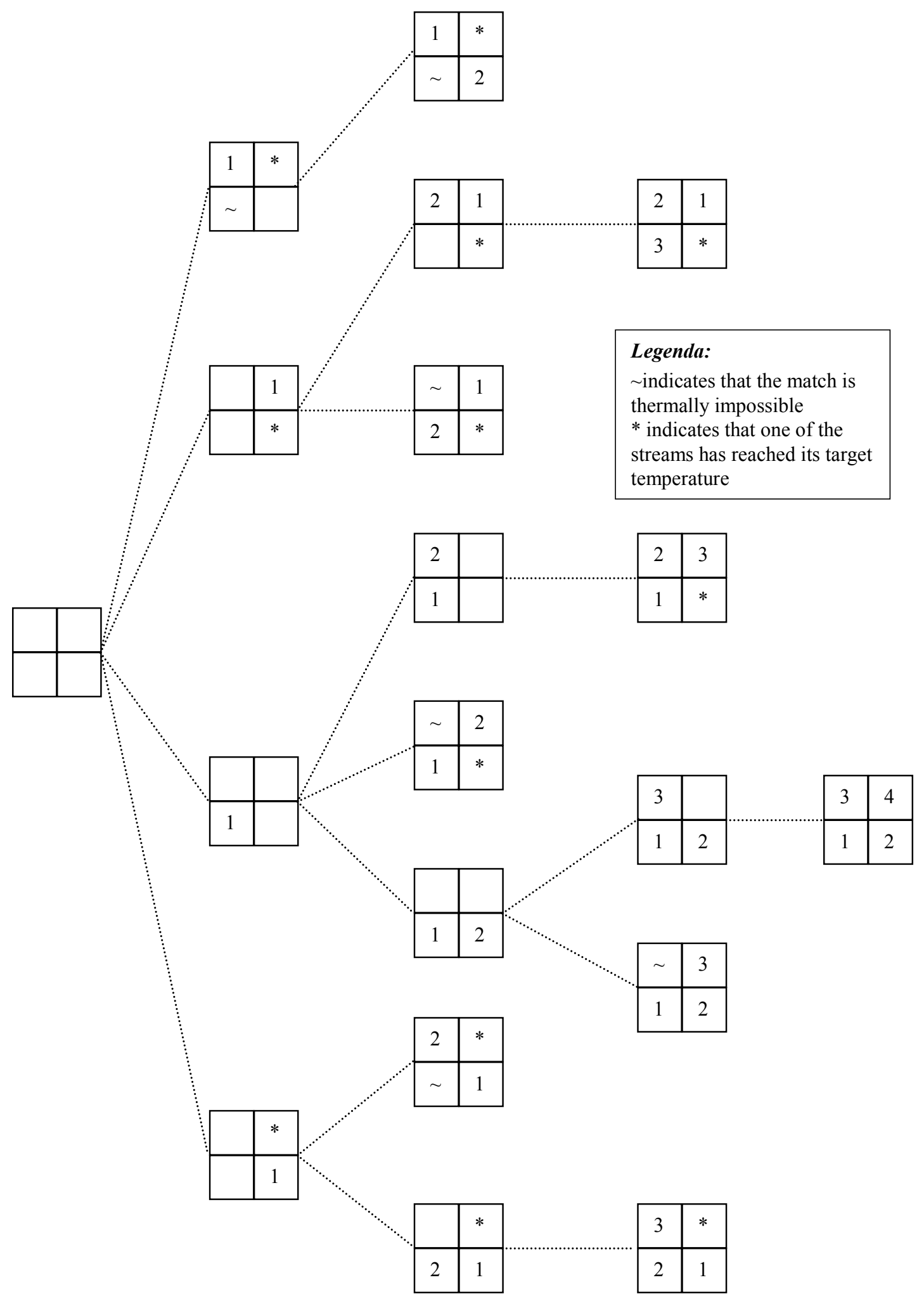


Figure 3. Configuration tree created by HENEA for the $2 X 2 \mathrm{HEN}$. In the elemental matrices, rows and columns represent hot and cold fluxes respectively, and the numbers identify the Heat Exchangers.

Rule 1): IF $\left(\mathrm{N}_{\mathrm{he}}>\alpha \mathrm{N}_{\min }\right)$

THEN (discard present configuration)

Where $\alpha$ is a tolerance parameter of the order of 1.1-1.2. Notice that if this version of the rule is applied, then configuration D1 (depicted in Figure 4a) would be tagged as "optimal" by HENEA. For comparison, Figure $4 b$ shows configuration $\mathrm{C} 4$, which has the minimum number of heat exchangers $(\mathrm{N}=5)$, but does not satisfy rule 4 (on the flux $\mathrm{H} 1$ there is a cold-utility fed cooler above the pinch temperature)

3. Rule \#3 is always enforced, because the Pho and Lapidus protocol employed here to construct the solution space allows the user to specify the TTD: so, this rule was enforced $a$ priori by the designer.

4. Rules \#4 and \#5 are very effective in pruning the configuration tree. Recall that these rules are a direct application of one of the basic principles of Pinch Technology.

5. Rules \#8 and \#9 do not apply, because they are automatically enforced by the Pho-Lapidus protocol.

6. Rule \#10 was intentionally excluded.

7. Rules \#11 and \#12 were switched off in the present application, because the configuration tree is very simple, and there are of course only 2 possible pairings for each step.

Finally, notice that the configuration tree has only 18 nodes instead of the 24 theoretically possible combinations indicated in Section 2: this is due to an automatic pruning enacted by the Pho-Lapidus algorithm. This indicates though that the performance of HENEA is sensitive to the protocol adopted to generate the feasible configurations.

\subsection{A 5-stream HEN (Example taken from (Kelahan and Gaddy 1977))}

To further test the capability of this procedure, HENEA was applied to a case originally discussed in (Linnhoff 1986), in which two hot- and three cold streams must be paired. The design specifications are reported in TABLE V. The problem is a threshold problem, with a pinch at the cold-utility end. The total possible number of combinations would be $\mathrm{N}_{\text {tot }}=343$, but the elimination of the physically impossible configurations, the cancellation of those which are topologically equal $^{5}$, and the application of the constraint

\footnotetext{
${ }^{5}$ Two configurations are said to be topologically identical if they are composed by the same number of heat exchangers, and if each heat exchanger in one configuration has an exact counterpart in the other. The original Pho-Lapidus procedure (Pho and Lapidus 1973) already suggested an automatic control loop to eliminate the double counting caused by such
}

$\mathrm{TTD}_{\min }=10 \mathrm{~K}$ reduce the number of possible configurations to 118. Application of the remaining 4 constraints as expressed by Rules 1,2,3,4 defined in Section 2.2 produces the following results (the rules are shown in TABLE VI, and some selected configurations are listed in TABLE VII):

- Rule 1 cuts 92 of the 118 possible configurations, resulting in a $78 \%$ pruning rate; consider that, this being a threshold problem, the minimum number is, according to Hohmann's rule, $\mathrm{N}_{\min }=5$ (there is no need for a heat exchanger on the cold utility side);

- Rule 2 discards 101 of the 118 possible configurations ( $85 \%$ pruning rate): one could question here the validity of an $\mathrm{ATD}_{\max }=$ $50 \mathrm{~K}$, which seems too restrictive;

- Rule 3 is again automatically enforced by the heat exchanger sizing algorithm;

- Rule 4, of course, does not discard any configuration.

A synoptic table is not shown for this case, but the results are discussed in detail in (Maiorano 2000): the result was that the constraints shown in TABLE VI couldn't be satisfied by any of the possible configurations. Then, Rules 1 and 2 were relaxed as follows:

a) Rule $1 *$ : minimum number of heat exchangers

is $N_{\text {min }}=N_{\text {min, }}$
b) Rule 2*: $\mathrm{ATD}_{\max }=70 \mathrm{~K}$

With these values, Rule 1 prunes 43 configurations and Rule 2, 86; but, more importantly, there is now one feasible network, i.e., there is one configuration that satisfies all constraints: the physical structure of this "optimal" HEN (D1 in TABLE VII) is shown in Figure $5 a$. It is noteworthy that this solution indicated by HENEA is the "optimal" one constructed in (Kelahan and Gaddy 1977). We also tried to release Rule 2 even further, by specifying a $\mathrm{TTD}_{\max }$ of $90 \mathrm{~K}$ : In this case, there are 4 additional possible configurations (D11, D12, E1 and E2 in TABLE VII): the selection in this case ought to be made on the basis of additional objective functions, and the best choice would be to perform a thermo-economic analysis of the 5 selected configurations, which is outside of the limits of this paper. Figures $5 b$ through $5 e$ report the results of a direct economic cost calculation. Notice that there is only a $0.5 \%$ (!) difference between the lowest and the highest annualised total cost.

\section{Conclusions}

repetitions, which are unavoidably produced by index permutations in any combinatorial algorithm.

Int.J. Applied Thermodynamics, Vol.3 (No.1) 
The work presented in this paper enables us to reach three important conclusions: first of all, it is indeed possible to perform a complete and successful evaluation of a Heat Exchanger Network on the basis of a synthetic tool based on physical principles rather than on a purely mathematical approach. This result had been only hinted at before, as the relevant references (Chen and Shen 1989, Sciubba and Melli 1998, Stephanopoulos 1986, Wang et. al. 1995) did not present numerical applications to real cases. Secondly, it is important to remark that, when dealing with "large HEN" problems, that would lead to a mathematically intractable formulation, the search for an optimal design can be reduced to the partial evaluation of a relatively small number of feasible con- figurations, and to the complete calculation of only few of them in the immediate vicinity of the optimum. In practice, a designer would never see tables like TABLE IV or TABLE VII shown here: s/he would be presented only with a very limited number of "workable" configurations (none in the case of TABLE IV; 1 in the case of TABLE VII; $\mathrm{V}$ if the ATD constraint in TABLE VII was released to $90 \mathrm{~K}$ ). This leads us to a very important theoretical result: Second Law principles (our "common sense rules") are for practical purposes much more powerful than any other technique used to date in effectively and correctly pruning the configuration tree. This encourages their further use in future AI applications to the Design of Thermal Systems.

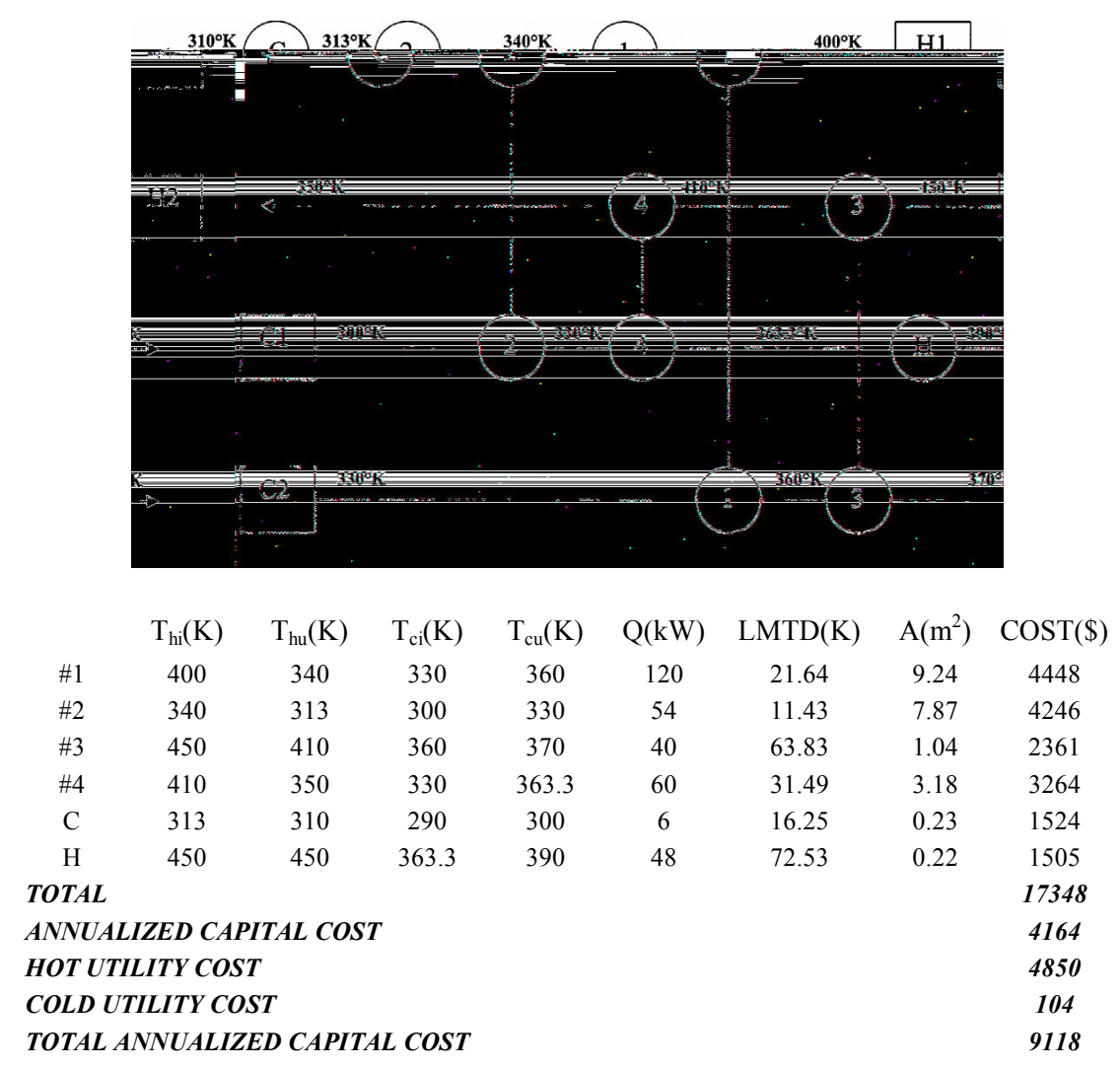

Figure 4a. Configuration D1 - MER Design

TABLE V DESIGN SPECIFICATIONS FOR EXAMPLE 3.2

\begin{tabular}{|c|c|}
\hline HOT STREAMS & COLD STREAMS \\
\hline $\mathrm{T}_{1 \mathrm{~h}, \text { in }}=522 \mathrm{~K}$ & $\mathrm{~T}_{1 \mathrm{c} \text {,in }}=311 \mathrm{~K}$ \\
$\mathrm{~T}_{1 \mathrm{~h}, \text { out }}=394 \mathrm{~K}$ & $\mathrm{~T}_{1 \mathrm{c}, \text { out }}=477.5 \mathrm{~K}$ \\
\hline $\mathrm{T}_{2 \mathrm{~h}, \text { in }}=477.5 \mathrm{~K}$ & $\mathrm{~T}_{2 \mathrm{c} \text {,in }}=339 \mathrm{~K}$ \\
$\mathrm{~T}_{2 \mathrm{~h}, \text { out }}=339 \mathrm{~K}$ & $\mathrm{~T}_{2 \mathrm{c}, \text { out }}=455 \mathrm{~K}$ \\
\hline $\mathrm{T}_{\mathrm{hu}}=509 \mathrm{~K}$ & $\mathrm{~T}_{3 \mathrm{c} \text {,in }}=366.5 \mathrm{~K}$ \\
& $\mathrm{~T}_{3 \mathrm{c}, \mathrm{out}}=477.5 \mathrm{~K}$ \\
\hline$\left(\mathrm{mc}_{\mathrm{p}}\right)_{\mathrm{h} 1}=16.62$ & $\left(\mathrm{mc}_{\mathrm{p}}\right)_{\mathrm{c} 1}=11.43$ \\
$\mathrm{~kW} / \mathrm{K}$ & $\left(\mathrm{mc}_{\mathrm{p}}\right)_{\mathrm{c} 2}=12.93 \mathrm{~kW} / \mathrm{K}\left(\mathrm{mc}_{\mathrm{p}}\right)_{\mathrm{c} 3}$ \\
$\left(\mathrm{mc}_{\mathrm{p}}\right)_{\mathrm{h} 2}=13.29$ & $=13.03$ \\
\hline
\end{tabular}

14 Int.J. Applied Thermodynamics, Vol.3 (No.1) 


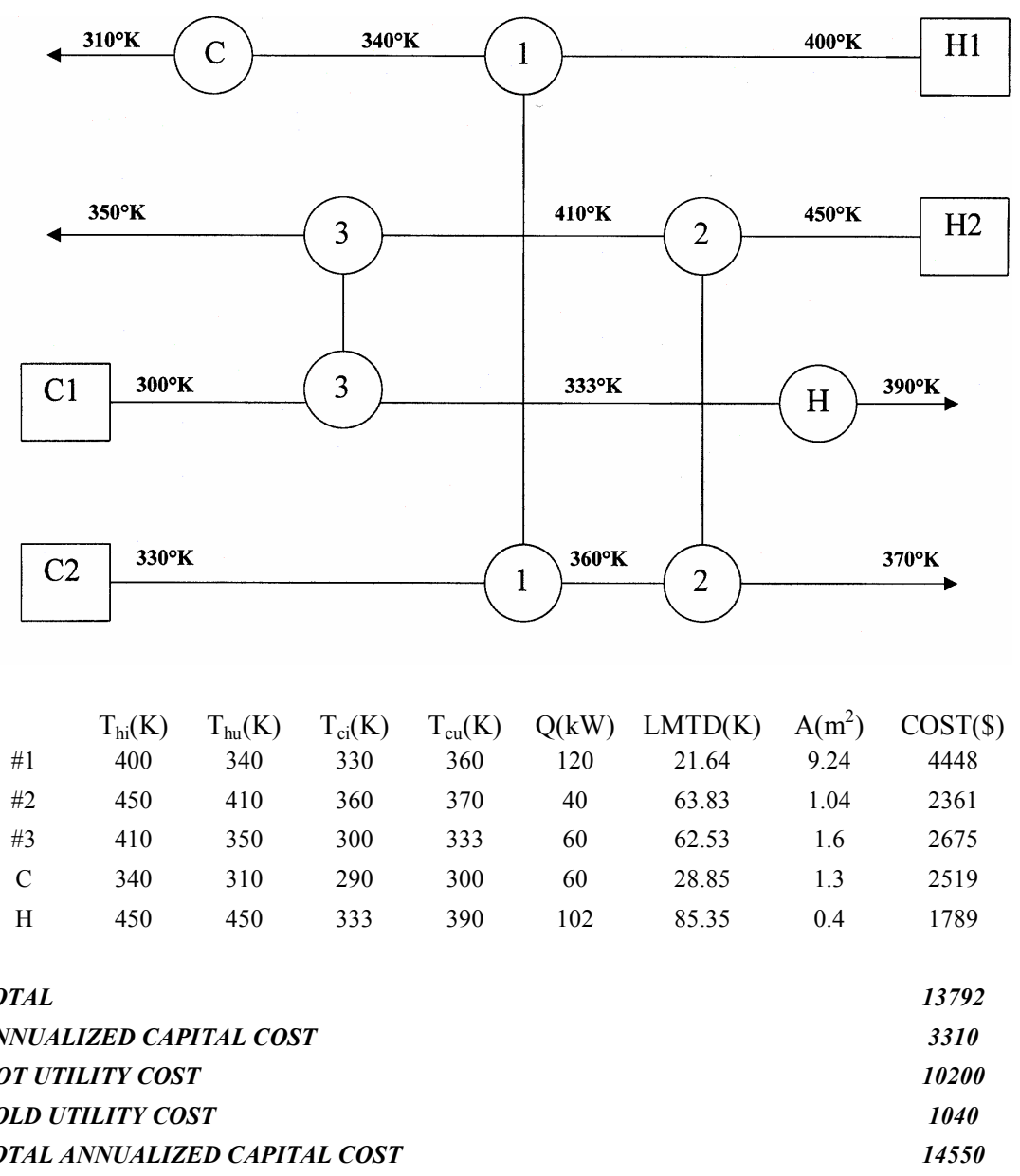

Figure $4 b$ Configuration $\mathrm{C} 4(\mathrm{~N}=\mathrm{Nmin})$

TABLE VI VALUES OF THECONSTRAINTSFOR THE PROPOSITIONALRULES APPLIED INEXAMPLE 3.2

\begin{tabular}{|l|c|c|}
\hline \multicolumn{1}{|c|}{ Constraint } & Rule where the constraint applies & $\begin{array}{c}\text { Numerical } \\
\text { value }\end{array}$ \\
\hline Minimum number of Heat Exchangers, $\mathrm{N}_{\min }$ & 1 & 5 \\
\hline Approach Temperature Difference, ATD & 2 & $50 \mathrm{~K}$ \\
\hline Terminal Temperature Difference, TTD & 3 & $10 \mathrm{~K}$ \\
\hline Pinch Temperature (Cold Stream) & 4.5 & $311 \mathrm{~K}$ \\
\hline
\end{tabular}

TABLE VII RESULTSOF THEAPPLICATIONOFHENEA TOEXAMPLE3.2: THEFIRST FIVE "FEASIBLE" CONFIGURATIONS

\begin{tabular}{|c|c|c|c|c|c|}
\hline Configuration & Rule \# $1\left(\mathrm{~N}_{\min }=6\right)$ & $\begin{array}{r}\text { Rul } \\
\left(\mathrm{ATD}_{\mathrm{m}}\right.\end{array}$ & $\begin{array}{l}2 \\
70 \mathrm{~K})\end{array}$ & $\begin{array}{c}\text { Rule \# } 3 \\
\left(\mathrm{TTD}_{\min }=10 \mathrm{~K}\right)\end{array}$ & $\begin{array}{c}\text { Rule \# } 4 \\
\text { (no cold utility } \\
\text { above } 311 \mathrm{~K} \text { ) }\end{array}$ \\
\hline D1 & 5 & & & & \\
\hline D11 & 5 & 87.5 & 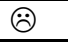 & & \\
\hline D12 & 6 & 81.5 & 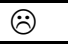 & & \\
\hline E1 & 6 & 74.5 & 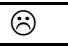 & & \\
\hline E2 & 6 & 84.8 & $\because$ & & \\
\hline
\end{tabular}




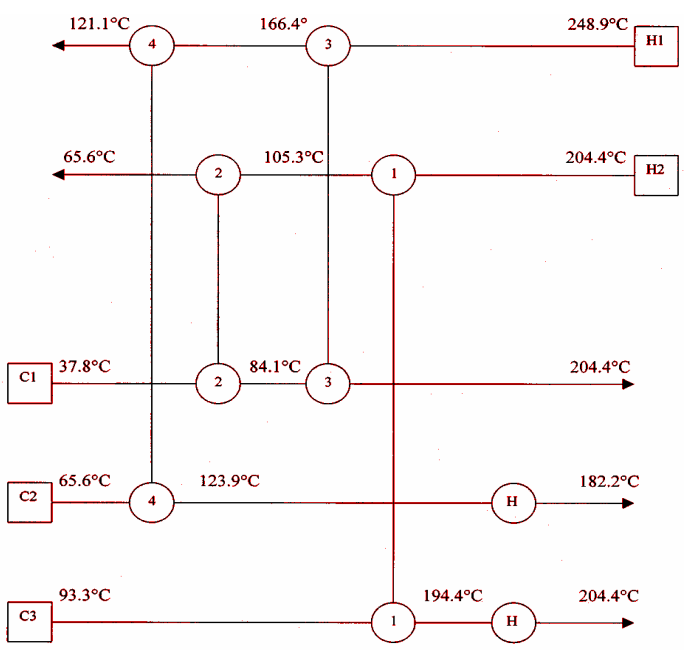

$\begin{array}{lcccccccc} & \mathrm{T}_{\mathrm{hi}}(\mathrm{K}) & \mathrm{T}_{\mathrm{hu}}(\mathrm{K}) & \mathrm{T}_{\mathrm{ci}}(\mathrm{K}) & \mathrm{T}_{\mathrm{cu}}(\mathrm{K}) & \mathrm{Q}(\mathrm{kW}) & \mathrm{LMTD}(\mathrm{K}) & \mathrm{A}\left(\mathrm{m}^{2}\right) & \mathrm{COST}(\$) \\ \# 1 & 204.4 & 105.3 & 93.3 & 194.4 & 1318 & 10.97 & 141.35 & 9810 \\ \# 2 & 105.3 & 65.6 & 37.8 & 84.1 & 528 & 24.35 & 25.51 & 5971 \\ \# 3 & 248.9 & 166.4 & 84.1 & 204.4 & 1369.5 & 61.48 & 26.21 & 6018 \\ \# 4 & 166.4 & 121.1 & 65.6 & 123.9 & 752 & 48.71 & 18.16 & 5411 \\ \mathrm{H} 1 & 283 & 283 & 123.9 & 182.2 & 752.1 & 127.74 & 5.21 & 3767 \\ \mathrm{H} 2 & 283 & 283 & 194.4 & 204.4 & 130 & 83.5 & 1.38 & 2563 \\ & \\ \text { TOTAL } & & & & & & \\ \text { ANNUALIZED CAPITAL COST } & & & & & & & \mathbf{8 3 5 4 0} \\ \text { HOT UTILITY COST } & & & & & & & \mathbf{8 9 0 9 2} \\ \text { COLD UTILITY COST } & \\ \text { TOTAL ANNUALIZED CAPITAL COST }\end{array}$

Figure 5a Configuration D1

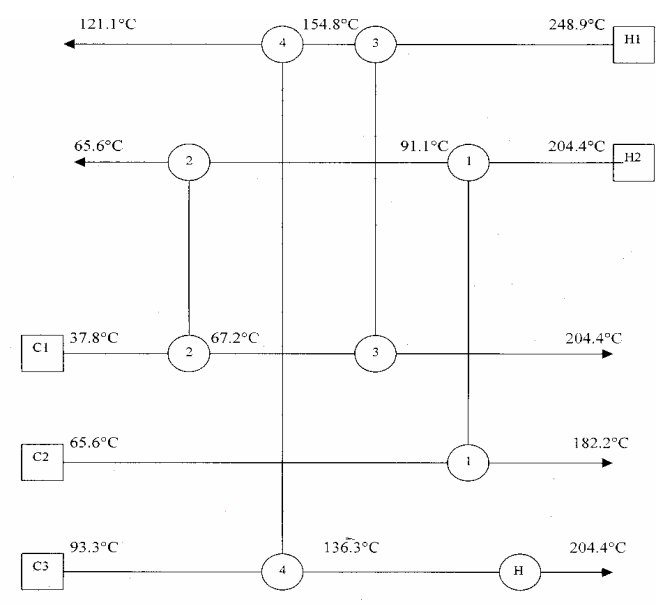

$\begin{array}{lcccccccc} & \mathrm{T}_{\mathrm{hi}}(\mathrm{K}) & \mathrm{T}_{\mathrm{hu}}(\mathrm{K}) & \mathrm{T}_{\mathrm{ci}}(\mathrm{K}) & \mathrm{T}_{\mathrm{cu}}(\mathrm{K}) & \mathrm{Q}(\mathrm{kW}) & \mathrm{LMTD}(\mathrm{K}) & \mathrm{A}\left(\mathrm{m}^{2}\right) & \mathrm{COST}(\$) \\ \# 1 & 204.4 & 91.1 & 65.6 & 182.2 & 1506.9 & 23.81 & 74.46 & 8146 \\ \# 2 & 91.1 & 65.6 & 37.8 & 67.2 & 2532.6 & 25.8 & 115.49 & 9252 \\ \# 3 & 248.9 & 154.8 & 67.2 & 204.4 & 1562.1 & 63.64 & 28.88 & 6190 \\ \# 4 & 154.8 & 121.1 & 93.3 & 133.3 & 559.4 & 24.52 & 26.84 & 6060 \\ \mathrm{H} & 283 & 283 & 136.3 & 204.4 & 885.3 & 109.13 & 7.18 & 4134 \\ & & & & & & & & \\ \text { TOTAL } & & & & & & & \mathbf{8 3 7 8 2} \\ \text { ANNUALIZED CAPITAL COST } & & & & & & \mathbf{8 9 4 1 5} \\ \text { HOT UTILITY COST } \\ \text { COLD UTILITY COST } \\ \text { TOTAL ANNUALIZED CAPITAL COST }\end{array}$

Figure 5b Configuration D11 


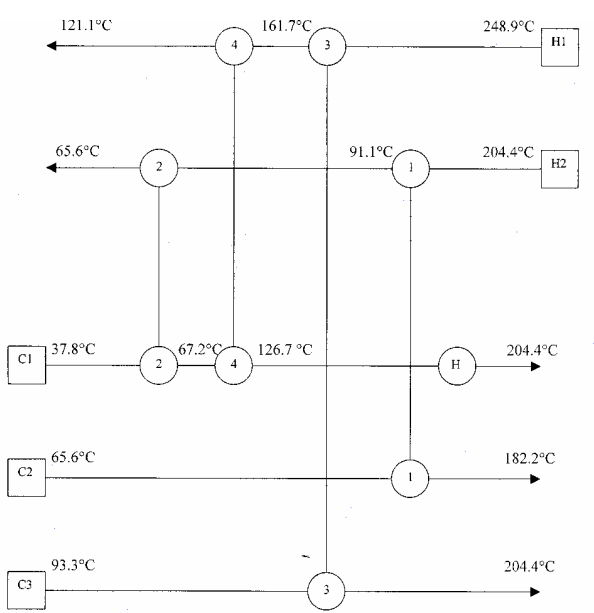

$\begin{array}{lcccccccc} & \mathrm{T}_{\mathrm{hi}}(\mathrm{K}) & \mathrm{T}_{\mathrm{hu}}(\mathrm{K}) & \mathrm{T}_{\mathrm{ci}}(\mathrm{K}) & \mathrm{T}_{\mathrm{cu}}(\mathrm{K}) & \mathrm{Q}(\mathrm{kW}) & \mathrm{LMTD}(\mathrm{K}) & \mathrm{A}\left(\mathrm{m}^{2}\right) & \mathrm{COST}(\$) \\ \# 1 & 204.4 & 91.1 & 65.6 & 182.2 & 1506.9 & 23.81 & 74.46 & 8146 \\ \# 2 & 91.1 & 65.6 & 37.8 & 67.2 & 339.2 & 25.8 & 15.47 & 5165 \\ \# 3 & 248.9 & 161.7 & 93.3 & 204.4 & 1447.5 & 55.6 & 30.63 & 6296 \\ \# 4 & 161.7 & 121.1 & 67.2 & 126.7 & 674 & 43.77 & 18.12 & 5407 \\ \mathrm{H} & 283 & 283 & 126.7 & 204.4 & 885.8 & 113.03 & 6.94 & 4094 \\ & \\ \text { TOTAL } & & & & & & & \mathbf{2 9 1 0 8} \\ \text { ANNUALIZED CAPITAL COST } & \\ \text { HOT UTILITY COST } \\ \text { COLD UTILITY COST } \\ \text { TOTAL ANNUALIZED CAPITAL COST }\end{array}$

Figure 5c The HEN configuration proposed by HENEA under the original set of constraints (D12 in TABLE VII)
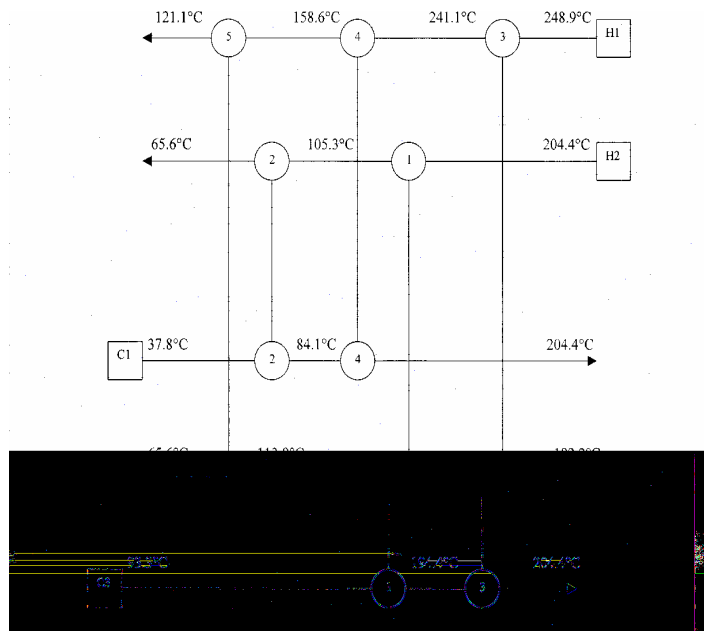

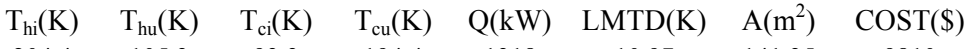

$\begin{array}{llllllll}204.4 & 105.3 & 93.3 & 194.4 & 1318 & 10.97 & 141.35 & 9810\end{array}$

$\begin{array}{llllllll}105.3 & 65.6 & 37.8 & 84.1 & 528 & 24.35 & 25.51 & 5971\end{array}$

$\begin{array}{llllllll}248.9 & 241.1 & 194.4 & 204.4 & 129.5 & 45.59 & 3.34 & 3311\end{array}$

$\begin{array}{llllllll}241.1 & 158.6 & 84.1 & 204.4 & 1369.5 & 53.39 & 30.18 & 6269\end{array}$

$\begin{array}{llllllll}158.6 & 121.1 & 65.6 & 113.8 & 622.5 & 49.96 & 14.66 & 5085\end{array}$

$\begin{array}{llllllll}283 & 283 & 113.8 & 182.2 & 882.4 & 132.06 & 5.91 & 3907\end{array}$

TOTAL

ANNUALIZED CAPITAL COST

34353
8245

HOT UTILITY COST

COLD UTILITY COST

TOTAL ANNUALIZED CAPITAL COST

89122

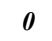

97367

Figure 5d - Configuration E1 


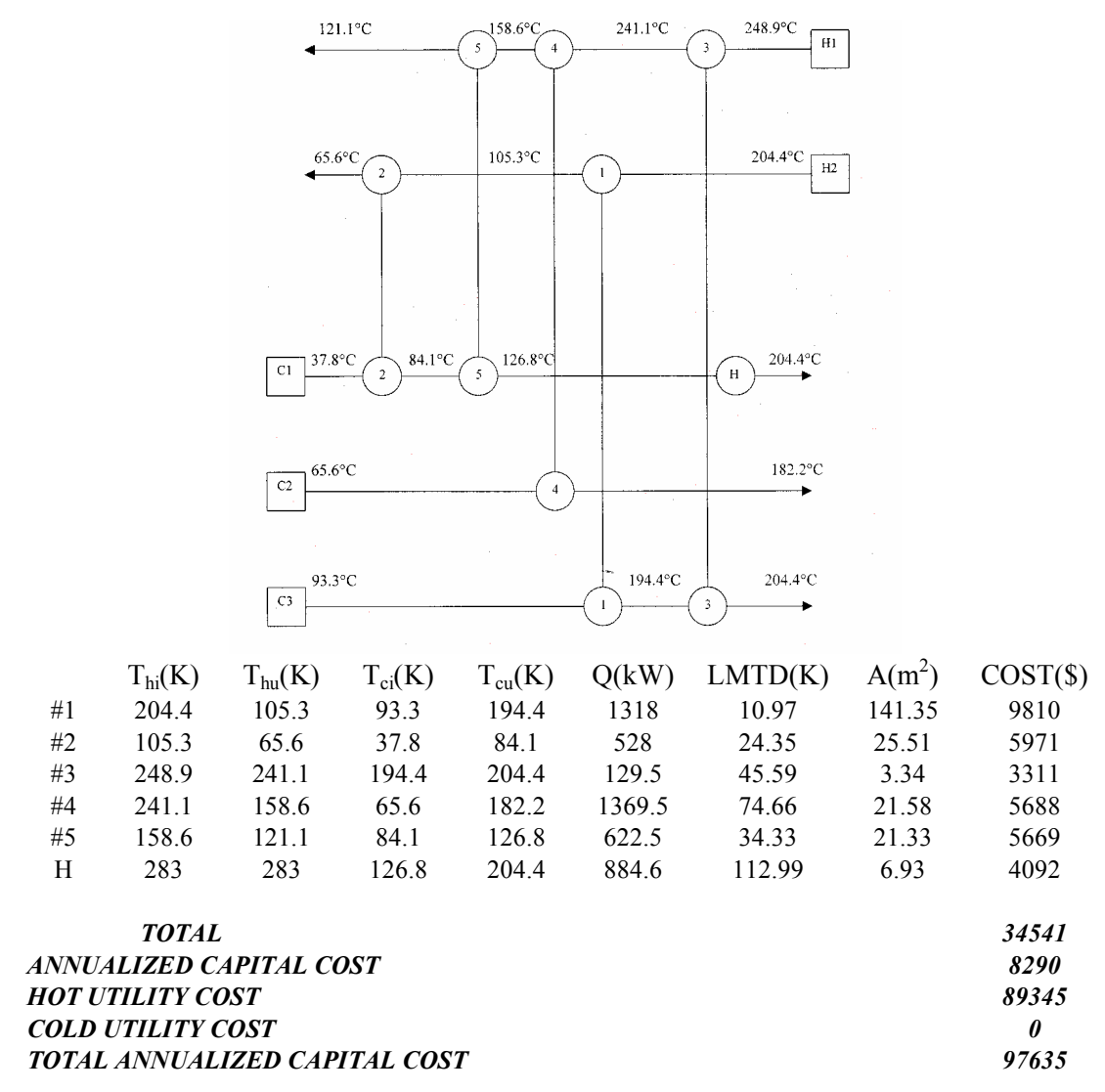

Figure 5e Configuration E2

In spite of the success of all practical applications it has been tested on, it is clear that HENEA is still afflicted by some shortcomings that require further work in the direction of the definition of the rules. The most important "open" issues are the following:

a) The need of proper treatment of stream splitting. The difficult part is to choose the proper stream recombination strategy, and to correctly manage the increase in the number of feasible configurations. The problem is solvable in principle, and stream splitting techniques can be applied under the Second Law guidelines, as shown in (Paoletti and Sciubba 1997): it is necessary to augment the Knowledge Base of the procedure, and to introduce proper additional Rules;

b) A more efficient handling of clear-cut cases. Configurations for which the energetic exchange is non-realistic ought to be discarded a priori: but in the present version of the code, they are discarded only after a mass and energy balance for all streams are carried out. Again, some meta-rules are needed to avoid

18 Int.J. Applied Thermodynamics, Vol.3 (No.1) this substantial computational effort, which is totally useless for the final result;

c) A more user-friendly interface. The possibility of "seeing" the configuration tree evolve is essential for the user's comprehension of the way HENEA performs its job. Also, individual heat exchanger schemes would help in quickly assessing the practical feasibility of a proposed configuration.

\section{References}

Ahmad, S. and Linnhoff, B., 1984, "Overall Cost Targets for Heat Exchanger Networks", Proceedings of IChemE Annual Meet., Bath

Ahmad, S. and Linnhoff, B., 1986, "SUPERTARGET: optimisation of a chemical solvents plant: different process structures for different economics", Proceedings of ASME WAM, Anaheim.

Bejan, A., Tsatsaronis, G. and Moran, M. J., 1996, Thermal Design and Optimisation, Wiley \& Sons.

Bi, L. and Ma, D., 1997, "Improvement of Heat Exchanger Net-work for an Ammonia plant using 
an Intelligent System", Proceedings of TAIES'97, Beijing

Chen, B. and Shen, S., 1989, "Development of an Expert System for the Synthesis of HEN", Comp.Chem.Eng., Vol.13, No.11/12.

Elshout, R. V. and Hohmann, E. C., 1979, The Heat Exchanger Network Simulator, Chem. Eng. Prog. No. 75.

XGaggioli, R., Sama, D., Qian, S. and El-Sayed, Y. M., 1991, "Integration of a new Process into an Existing Site: a Case Study in the Application of Exergy Analysis", J.Eng. for Gas Turb. and Power, No. 113.

Garland, W. M. J., 1996, "The Role of Knowledge-Based Systems in Heat Exchanger Selection, Design and Operation", in New Developments in Heat Exchangers, N.Afgan et al. (Eds.), Gordon \& Breach

Gundersen, T. and Näss, L., 1988, “The Synthesis of Cost Optimal Heat Exchanger Networks: an Industrial Review of the State of the Art", Comp.Chem.Eng,. Vol.12, No.6.

Hohmann, E. C., 1971, “Optimum Networks for Heat Exchange", PhD. Thesis, University of South California

Hohmann, E. C. and Lockhart, F. J., 1976, "Optimum Heat Exchanger Network Synthesis”, Proceedings of AIChE Meet., Atlantic City

Huang, F. and Elshout, R. V., 1976, "Optimising the Heat Recovery of Crude Units", Chem. Eng. Progr., Vol. 72, No.1

Kelahan, R. C. and Gaddy, J. L., 1977, "Synthesis of Heat Exchange Networks by Mixed Integer Optimisation", AIChE Journal, No.23

Linnhoff, B., 1986, "Pinch Technology for the Synthesis of Optimal Heat and Power Systems", Proceedings of ASME WAM, Anaheim

Linnhoff, B. and Alanis, F. J., 1991, "Integration of a new Process Into an Existing Site: A Case Study in the Application of Pinch Technology", J.Eng. for Gas Turb. and Power, No.113

Maiorano, M., 2000, "An Expert System for the Synthesis of HEN", ME. Thesis, University of Roma 1

Mikkelsen, J. and Quale, B., 1997, "Economic optimisation of Heat Exchanger Network Synthesis Using a Combinatorial Approach", Proceedings of TAIES'97, Beijing

Moran, M. J. and Shapiro, H., 1995, Fundamentals of Engineering Thermodynamics, Wiley \& Sons.
Ngaw, L. T., 1998, "HEN Synthesis using HENCALC and Second Law Insights", MS. Thesis, University of Massachusetts - Lowell

Paoletti, B. and Sciubba, E., 1997, “Artificial Intelligence Applications in the Design of Thermal Systems", Developments in the Design of Thermal Systems, R.Boehm (Ed.), Cambridge U.Press

Pho, T. K. and Lapidus, L., 1973, "Topics in Computer-Aided Design: Part 2. Synthesis of Optimal Heat Exchangers Networks by Tree Searching Algorithms", AIChE Journal, Vol.19, No.6

Ponton, J. W. and Donaldson, R. A. B., 1974, A fast method for the synthesis of optimal Heat Exchanger Networks, Chem.Eng.Sci., No.29

Roosen, P. and Gross, B., 1995, "Optimisation Strategies and Their Application to Heat Exchanger Network Synthesis", Proceedings of Eurotherm Seminar, RWTH Aachen.

Sama, D. A., Gaggioli, R. A. and Qian, S., 1989, "A Common-sense Second Law Approach for Improving Process Efficiencies", Proceedings of TAIES 1989, Beijing, Int. Academic PublishersPergamon Press

Sama, D. A., 1995a, "The Use of the Second Law of Thermodynamics in Process Design", JERT, Vol. 117, No.9.

Sama, D. A., 1995b, "Second Law insight analysis compared with Pinch Analysis as a Design Method", Proceedings of Second Law Analysis of Energy Systems: Towards the 21st Century.

Sciubba, E. and Melli, R., 1998, Artificial Intelligence in Thermal Systems Design: Concepts and Applications, Nova Science Pub.

Stephanopoulos, G., 1986, Expert Systems and Computing Environments for Process Systems Engineering, Comm. AIChE, No. 9.

Szargut, J. and Sama, D. A., 1995, "Practical Rules for the Reduction of Energy Losses Caused by the Thermodynamic Imperfection of Thermal Processes", Proceedings of. II Int. Therm. Energy. Conf., Agadir, Morocco.

Tribus, M. and Evans, R. B., 1962, Thermoeconomics, Eng. Dept. Rep. N.62/63, U. of California at L.A.

Wang, Q., Zhu, J. Y., Shu, Y. Q., Rao, M. and Chuang, K. T., 1995, “An Intelligent Design Environment for Conceptual Process Design”, Eng. Applic. AI, Vol.8, No. 2. 